\title{
Study on Improving the Anticorrosion Ability of Chemical Machinery Zhenhui Luan ${ }^{\mathrm{a}}$, Chao Liu ${ }^{\mathrm{b}}$, Shan Wang ${ }^{\mathrm{c}}$, Yihua Li ${ }^{\mathrm{d}}$ Mechanical Engineering school, Anhui University of Science and Technology, Huainan, Anhui, 232001, China \\ azhluan@aust.edu.cn, b851795947@qq.com, ' $305924918 @ q q . c o m$, \\ dyh511@126.com
}

Keywords: chemical machinery, chemical corrosion, anticorrosion ability, anticorrosion design, green design.

\begin{abstract}
In the chemical industry, chemical machinery is essential production equipment, the corrosion problems of the chemical equipment will bring negative economic problems to the enterprises. In order to improve the anticorrosion ability of chemical machiery, the types of corrosion were introduced, the principle of chemical corrosion and electrochemical corrosion of metal were analysed. The discussions focus on the anticorrosion design, safe design, design for disassembly and green design of the chemical machiery and the method to control corrosion of the chemical machiery. The research indicates that the methods can improve the anticorrosion ability of the chemical machiery.
\end{abstract}

\section{Introduction}

At present, a major problem that the chemical machinery faces is how to improve the anticorrosion ability of chemical machinery, because it can not only improve the chemical mechanical service life but also reduce economic input of the enterprise. Corrosion is to make material consumption and some damage after chemistry or chemical action. After corrosion, the mechanical equipment's shape, color and mechanical properties are subject to different degrees of damage, so that the chemical enterprise has suffered severe economic losses. So, how to improve the anticorrosion ability of chemical machinery has become the key problem in the chemical enterprise $^{[1]}$.

\section{Causes of equipment corrosion}

The chemical property of most metals is lively, so that the metal itself is easy to be corroded. In addition, because of the special environment the chemical equipment in, the surrounding has a large number of hazardous substances, such as sulfide, salt fog, sulfur dioxide, hydrogen sulfide, etc. Due to long-term exposure and some environment not only humid but also hyperthermia, the metal equipment will be corroded, thus cause damage.

\section{Types of equipment corrosion}

Metal equipment corrosion is mainly divided into two categories: chemical corrosion and electrochemical corrosion. Chemical corrosion is refers to the surface of metal equipment and its surroundings in the medium chemical reaction happened and then produce new material, a kind of metallic oxide, therefore causes the destruction of the metal. Chemical corrosion generally takes place in the environment of high temperature drying, and metal contacts with the environment in the medium directly. Electrochemical corrosion is refers to the metal equipment in contact with the electrolyte solution of corrosion by electrode. The innate character of corrosion is redox reaction. Electrochemical corrosion usually happens in a humid environment ${ }^{[2]}$.

On the other hand, according to the reasons of corrosion, corrosion common can be divided into high temperature oxidation corrosion, peeling corrosion, pitting corrosion, crevice corrosion, inter 
granular corrosion, welding stress corrosion, abrasion corrosion, vibration industrial atmospheric corrosion, marine atmospheric corrosion, fatigue corrosion.

For chemical enterprise, electrochemical corrosion is the most serious corrosion.

\section{Chemical mechanism of equipment corrosion}

Electrochemical corrosion mechanism. The electrochemical corrosion of metal is refers to the metal surface and the ion conducting medium damage produced by electrochemical action. Either by the electrochemical mechanism of corrosion reaction consists of at least an anode and a cathode reaction, and the ion current to flow through the medium and the inside of the metal electron flow together, at the time of metal ions from the metal anode reaction antioxidant components to the medium to absorb electrons from the anode reduction process. Corrosion of carbon steel in acid, $\mathrm{Fe}$ in anode area by oxidation of $\mathrm{Fe}^{2+}$ ions, electrons from the anode ( $\mathrm{Fe}$ ) flow of energy that is released to the steel in the anode $(\mathrm{FeC})$, absorbed by $\mathrm{H}^{+}$thus reduction of oxygen and its equation is $^{[3]}$

$$
\mathrm{Fe}+2 \mathrm{H}^{+} \rightarrow \mathrm{Fe}^{2+}+\mathrm{H}_{2}
$$

The electrochemical corrosion formed a short circuit battery inside the metal, in the cathode reduction reaction consumed anode of electronic, current is not an isothermal. Therefore in the electrochemical corrosion if promote metal anode ionization will accelerate the corrosion which will result in the rapid destruction of chemical equipment.

Industrial atmospheric corrosion mechanism. In some areas, industrial pollution is serious, the air can contain high concentration of corrosive medium, such as sulfur dioxide, carbon dioxide, hydrogen sulfide, halide and industrial dust, the acidic gas in humid air can form inorganic acid, if chemical machinery equipments contact with this media, they will be seriously damaged by corrosion[4].

The corrosion of industrial atmosphere in which mechanical equipment containing $\mathrm{Fe}$ is chemical corrosion and electrochemical corrosion in the form of combination, among them the sulfur dioxide corrosion is most serious, the reason is that it can form acid rain and have the effect of catalyst.

By above knowable, the nature of chemical corrosion and electrochemical corrosion is a oxidation process that metal atom lose its electron to be ion, the main difference is that the chemical corrosion is a metal with its surrounding medium under the condition of high temperature drying with the reaction, and the process of electrochemical corrosion must be in a humid environment.

\section{The anticorrosion design of chemical equipment}

As we all know that the metal corrosion damage is one of the main damage forms, therefore, when purchasing machinery and equipment, we should consider and pay attention to this factor, including installation to use after choose and buy, and when we design some accessories for the mechanical equipment, the arguably functions of equipment components and equipment in the corrosive environment of anticorrosive design is equally important ${ }^{[4]}$.

Selection of materials. At present, the material the manufacturing machinery and equipment used is basically ordinary carbon steel, the material's advantages are its low price and simple to process. In the ordinary course of business environment, the corrosion of the damage is not serious, but if it often at relatively high concentrations of corrosive medium, it will subject to severe corrosion. Commonly used Q235 steel, for example, the speed of its corrosion in acid salt medium environment is as high as $0.5 \sim 1.0 \mathrm{~mm} / \mathrm{a}$, although most enterprises will daub anti-corrosion materials on the surface of equipment on a regular basis in the process of production, however, if the surface of the equipment once have scratches or partial loss, the electrochemical corrosion will happen soon and accelerate the diffusion, and this will seriously affect the service life of the equipment. So, this kind of steel is not a suitable raw material for field of chemical industry. When choosing materials, we should choose corrosion resistant steel as far as possible, although the price 
of such steel is more expensive as ordinary materials, but looked from the overall, the economic benefit it brings is much higher than normal steel.

Structure design of anti-corrosion. If the structure of mechanical equipment is unreasonable, it would produce corrosion ${ }^{[5]}$. Therefore, we had fully considered the structure design of anti-corrosion as below in the process of structure design of chemical machinery.

(1) The shape of the equipment should be concise as far as possibly.

(2) The material of equipment should be the same kind of metal, to avoid a variety of metal materials.

(3) To avoid crack of the equipment in the aspect of structure as far as possible, to prevent surface scratches, good for cleaning.

(4) To avoid weld defects, to avoid stress concentration.

Strength design of anti-corrosion.In chemical machinery, the environment has strong corrosive, so the designers should also pay attention to the strength of the anti-corrosion design in the strength design of mechanical. In the process of the strength of the mechanical equipment design, we not only to meet the requirements of equipment itself on the strength, but also to consider the design of the corrosion allowance, generally the corrosion allowance twice the corrosion depth of equipment lifetime.

\section{Safe design of chemical equipment}

Safety device. Safety device is an essential safety accessory, which is installed on the chemical equipment. When the safety device is designed, the non-controllability in reaction must be considered, the reaction mass must be properly disposed when the equipments "stop" suddenly. This kind of device can prevent people to entry danger zone. All moving parts, such as driving bands, belt pulleys and flywheels and so on, must be covered or shaded.

Control device. Control device does not defend workers directly, but when the workers entry danger zone, or there are the poison gas, exhaust gas and other harmful factors, the control device can switch off power supply, stop the chemical equipment ${ }^{[6]}$.

\section{Design for disassembly of chemical equipment}

Design for disassembly is to make the chemical equipment good disassembly performance in design stage. In design for disassembly, we followed the principles below.

(1) Under the premise of meet the requremenrs, to simplify design of the equipment to reduce the disassembly difficulty.

(2) To use material compatible with good performance.

(3) For some parts which strucure and function are similar, to use standard and general parts, and this can reduce the kinds and numbers of withdrawal tool.

\section{Green design of chemical equipment}

Green design is to realize the sustainable development of human, have a high quality living environment, enjoy healthy life. Traditional design thought alone about the function, quality, cost and lifetime of the products, but green design thinks mainly about environment and sustainabke development of human ${ }^{[7]}$.

In green design of chemical equipment, we followed the principles below.

(1) To select green material.

(2) To make energy conservation design.

(3) To make design for recoverability.

\section{The method to control the corrosion}

For the method of control mechanical metal equipment, it can be roughly divided into two 
aspects, on the one hand, by selecting strong corrosion resistance of metal, and besmear brushes anticorrosive material processing on its surface. On the other hand, anticorrosive processing for the environment the machinery and equipment in, by reducing the harmful material, humidity and temperature in the environment to achieve the goal of reducing corrosion. Of course, people can also make use of electrochemical protection of metal equipment by sacrificing anode to protecting cathode. For chemical corrosion control, people should conduct from multiple aspects at the same time, only in this way can people make the losses to minimize caused by corrosion, so as to prolong the service life of equipment.

For chemical corrosion control, we followed the principles below.

(1) The construction of a reasonable crack is the key to prevent crevice corrosion, so we always build a reasonable crack into the chemical equipment.

(2) The surface of the chemical equipment was daubed with antirust paint, and always try to select excellent antirust paint.

(3) To pay special attention to spraying weld coating when spraying antirust paint.

(4) To prevent the residual water retention on the chemical equipment.

(5 )To train employees, to make them know well knowledge about corrosion.

\section{Summary}

Chemical equipment is very important to chemical enterprise and it is used frequently, so the requirement of chemical machinery and equipment is taller than others. So we can improve the anticorrosion ability of chemical machinery from the aspects such as material selection, design. Chemical enterprise can avoid the impact of chemical enterprise economic benefits due to corrosion.

Through years of practice, we had tried to design the chemical equipments in anticorrosion design, green design and design for disassembly, and tried to control the corrosion of the equipments from many aspects, and the effect of the work is good.

\section{References}

[1] Wei Song. Chemical Machinery Corrosion Resisitance. HeiLongJiang Science And Technology Information, 2011(4), pp18 (In Chinese).

[2] Wu Youqing. The Development and Prospects of Technology of Chemical Machinery. Value Engineering, 2013(11), pp4-5 (In Chinese).

[3] Maiqun Zhao, Ali Lei. Corrosion and Protection of Metals. National Defence Industry Press, 2002 (In Chinese)

[4] Xu Haiyuan. Analysis of improving chemical machinery anti-corrosion ability effective method. HuNan Agricultural Machinery, vol.40, No.1, pp101-102, 2013 (In Chinese).

[5] Xia Chen. Research on Improving the Antisepticise Ability of Chemical Industry Equipments. Guangdong Chemcal Industry, vol.36, No.194, pp.205-206, 273, 2009 (In Chinese).

[6] Zhang Jingying. Corrosive Reason of Chemical Engineering Machinery and Anti-Corrosion Method. Technology \& Development of Chemical Industry, vol.41, No.3, pp48-50, 2012 (In Chinese)

[7] Sun Yanbao. Green Design Concept in the Light of Mechanical Industry. Equipment Manufacturing Technology, 2011(4), pp212-214 (In Chinese). 